(2) Open Access Full Text Article

\title{
Prospective study on nanoparticle albumin-bound paclitaxel in advanced breast cancer: clinical results and biological observations in taxane- pretreated patients
}

\author{
This article was published in the following Dove Press journal: \\ Drug Design, Development and Therapy \\ 20 November 2015 \\ Number of times this article has been viewed
}

\author{
Alessandra Fabi' \\ Diana Giannarelli ${ }^{2}$ \\ Paola Malaguti' \\ Gianluigi Ferretti' \\ Sabrina Vari' \\ Paola Papaldo' \\ Cecilia Nisticò' \\ Mauro Caterino 3 \\ Roy De Vita ${ }^{4}$ \\ Marcella Mottolese ${ }^{5}$ \\ Laura lacorossi ${ }^{6}$ \\ Francesco Cognetti' \\ 'Department of Medical Oncology, \\ ${ }^{2}$ Biostatistic Unit, ${ }^{3}$ Service of \\ Radiology, ${ }^{4}$ Operative Unit of \\ Plastic and Reconstructive Surgery, \\ Department of Pathology, Regina \\ Elena National Cancer Institute, \\ Rome, Italy; ${ }^{5}$ Department of Pathology, \\ ${ }^{6}$ Department of Biomedicine and \\ Prevention, University of Rome \\ "Tor Vergata", Rome, Italy
}

Correspondence: Alessandra Fabi Department of Medical Oncology, Regina Elena National Cancer Institute, Via Elio Chianesi 53, Rome, Italy

Tel +39065I446919

Fax +3906 52665637

Email alessandra.fabi@virgilio.it
Background: There is a deep need to improve the care of metastatic breast cancer (MBC) patients, since even today it remains an incurable disease. Taxanes are considered the most effective cytotoxic drugs for the treatment of MBC, both in monotherapy and in combined schedules, but the need for synthetic solvents contributes to the severe toxicities and may have a negative impact on the efficacy. Nanoparticle albumin-bound paclitaxel ( $N a b$-paclitaxel) is a colloidal suspension of paclitaxel and human serum albumin initially developed to avoid the toxicities associated with conventional taxanes.

Patients and methods: The aim of this prospective, single-center open-label, noncomparative study was to evaluate the efficacy and safety of $n a b$-paclitaxel in MBC patients pretreated with taxanes. The patients were treated with $n a b$-paclitaxel as a single agent, $260 \mathrm{mg} / \mathrm{m}^{2}$ on day $1 \mathrm{of}$ each 3-week cycle or $125 \mathrm{mg} / \mathrm{m}^{2}$ weekly. The primary endpoint was the overall response rate (ORR). Secondary objectives were duration of response, clinical benefit rate, progression-free survival (PFS), overall survival, and safety.

Results: A total of 42 patients (median age 48 years, median Eastern Cooperative Oncology Group performance status 0, triple-negative MBC 19\%, all pretreated with a taxane-based therapy, mainly in advanced disease) were enrolled in the study. The ORR was $23.8 \%$, including one complete response (2.4\%) and nine partial responses $(21.4 \%)$; the disease control rate was $50 \%$. The median duration of response was 7.2 months. After a median follow-up of 9 months, the median PFS was 4.6 months. ORR and PFS were similar irrespective of the previous chemotherapy lines, metastatic sites, and biomolecular expression. Nab-paclitaxel was well tolerated, and the most frequent treatment-related toxicities were mild to moderate (grades 1-2).

Conclusion: This real-life study shows that nab-paclitaxel has a significant antitumor activity and a manageable safety profile in patients pretreated with taxanes and experiencing a treatment failure after at least one line of chemotherapy.

Keywords: $n a b$-paclitaxel, metastatic breast cancer, anthracyclines

\section{Introduction}

There is a deep need to improve the care of metastatic breast cancer (MBC) patients, since today, despite the output of new drugs in the therapeutic landscape, it remains an incurable disease. The therapeutic objectives are palliative, mainly in controlling symptoms, improving/maintaining quality of life, and prolonging survival, and carefully balancing the efficacy and toxicity of the treatment. ${ }^{1,2}$

Currently, taxanes (paclitaxel and docetaxel) are considered the most effective cytotoxic drugs for the treatment of $\mathrm{MBC}$, both in monotherapy and in combined 
schedules, ${ }^{3}$ and drugs of choice, according to the most recent international guidelines. ${ }^{1,4}$ Despite the well-known clinical activity of taxanes against most tumors, it has been demonstrated that the need for synthetic solvents (because of drugs' hydrophobicity) contributes to the severe toxicities, such as hypersensitivity reactions and peripheral neuropathy. In addition, these solvents may have a negative impact on efficacy due to an entrapment of active drug in plasma micelles, leading to increased systemic drug exposure, decreased drug clearance, nonlinear pharmacokinetics, and lack of dose-dependent antitumor activity. 5,6

Nanoparticle albumin-bound paclitaxel ( $\mathrm{Nab}$-paclitaxel) is a colloidal suspension of paclitaxel and human serum albumin initially developed to avoid the toxicities associated with solvents. This drug utilizes the natural properties of albumin: the physiological transport of lipophilic molecules in bloodstream and a preferential deliver paclitaxel to tumors by biologically interacting with albumin receptors that mediate drug transport. ${ }^{7} \mathrm{Nab}$-paclitaxel allows the safe infusion of significantly higher doses of paclitaxel than the doses used with standard paclitaxel therapy, with shorter infusion schedules (30 minutes vs 3 hours, respectively) and no premedication. ${ }^{5} \mathrm{Nab}$-paclitaxel was developed to improve the already known antitumor activity of conventional paclitaxel in terms of increased efficacy and better tolerability.

Several pivotal trials evaluated the efficacy and safety of $n a b$-paclitaxel in the treatment of MBC patients, even in heavily pretreated, taxane-refractory women, both at the dose of $260 \mathrm{mg} / \mathrm{m}^{2}$ as a three-weekly (q3w) regimen and $150 \mathrm{mg}$ / $\mathrm{m}^{2}$ weekly. These studies showed that $n a b$-paclitaxel was superior to the other conventional taxanes in terms of overall response rate (ORR) and progression-free survival (PFS), with a favorable toxicity profile. ${ }^{5,8-11}$ Additional studies demonstrated that $n a b$-paclitaxel is also active against more aggressive forms of MBC, such as triple-negative tumors. ${ }^{12,13}$

The objective of this study was to analyze the efficacy and toxicity of nab-paclitaxel in taxane-pretreated MBC patients in a real-world setting and to define its activity according to the clinical characteristics and biological features.

\section{Patients and methods}

\section{Study setting and design}

The aim of this prospective, single center open-label, noncomparative study was to evaluate the efficacy and safety of nab-paclitaxel in MBC patients pretreated with taxanes. All data were stored in a centralized database and analyzed at the Regina Elena National Cancer Institute in Rome. During treatment, all adverse events related to the treatment were recorded on the electronic case report form. The study was conducted according to the Declaration of Helsinki; all patients provided a written informed consent before undergoing any study-specific procedure.

The primary endpoint was the ORR, defined as the rate of patients with a complete response (CR) or partial response (PR). Secondary objectives were duration of response, clinical benefit rate (CBR), PFS, overall survival (OS), and safety.

Treatment activity was assessed every 12 weeks according to Response Evaluation Criteria in Solid Tumor criteria. ${ }^{14}$ Overall response was defined as the best confirmed response in each patient from the date of enrollment until the end of the study. Response duration was calculated from the start of the treatment to the first evidence of disease progression, and CBR was defined as the proportion of patients with $\mathrm{CR}$, PR, or stable disease (SD) lasting $\geq 6$ months. CR and PR were confirmed after 4 weeks from the last assessment by computed tomography scan. PFS was defined as the time period ranging from the enrollment to the first documented progression and OS the time period between study enrollment and date of death. In case of brain metastasis, a magnetic resonance imaging was performed every 12 weeks. Patients who received at least one dose of study drug were considered evaluable for safety analysis.

Toxicity was assessed every 3 weeks or weekly according to the used schedule and to the National Cancer Institute Common Terminology Criteria for Adverse Events (Version 4.02). Toxicity was evaluated through clinical evaluation, complete blood cell count, and full serum chemistry and graded according to the National Common Toxicity Criteria.

\section{Patient population}

All patients ( $\geq 18$ years) previously treated with taxanes in the adjuvant or metastatic setting were consecutively enrolled in the study. The eligibility criteria were histological diagnosis of invasive breast cancer, presence of metastatic disease, and previous treatment with at least one chemotherapy for advanced disease. Patients should have an Eastern Cooperative Oncology Group performance status $\leq 2$ and a life expectancy of $\geq 3$ months. Patients with previously controlled neoplastic disease within 5 years before study entry were considered for inclusion. Patients with asymptomatic central nervous system metastases were eligible, and treatment with surgery or radiation therapy of brain lesions should have been performed no $>3$ months before study entry. Patients with a grade $>2$ of peripheral neuropathy due to previous neurotoxic drugs were excluded from the study treatment. An absolute 
neutrophil count $>1,500 / \mathrm{mL}$, platelet count $>100,000 / \mathrm{mL}$, bilirubin $<2 \mathrm{mg} / \mathrm{dL}$, aspartato amino-transferase (AST)/ alanina amino-transferase (ALT) $<2$ times the upper normal limit, and creatinine $<1.5 \mathrm{mg} / \mathrm{dL}$ were required. Pregnancy and breastfeeding were conditions for exclusion. Other concomitant anticancer therapies were not admitted, and radiotherapy to extracranial sites or hormonal therapy should terminate at least 1 month before starting nab-paclitaxel treatment.

\section{Schedule of treatment}

All the enrolled patients were treated with $n a b$-paclitaxel as a single agent, at the dose of $260 \mathrm{mg} / \mathrm{m}^{2}$ as a 30-minute intravenous infusion on day 1 of each 3-week cycle or $125 \mathrm{mg} / \mathrm{m}^{2}$ as a 30-minute intravenous infusion weekly. Each vial contains $100 \mathrm{mg}$ of paclitaxel (as paclitaxel albumin). After reconstitution, each milliliter of suspension contains $5 \mathrm{mg}$ of paclitaxel (as paclitaxel albumin). The reconstituted medicinal product contains $\sim 425 \mathrm{mg}$ sodium per dose.

The drug was administered on an outpatient basis without steroid or antihistamine premedication, specialized intravenous infusion sets, or inline filtration.

The treatment was administered until documented disease progression, unacceptable toxicity, or refusal of the patient. The choice of schedule was at the discretion of the investigator taking into account the age of the patient, performance status, and burden of disease.

Grade 3 or 4 toxic effects were managed by dose modifications. Concomitant treatments that did not interfere with the evaluation of $n a b$-paclitaxel, including the use of bisphosphonates, could be given at the investigator's discretion.

\section{Histopathological analysis}

Histopathological information was directly documented from the original pathology reports. Tumor histotype, grading, expression of estrogen receptors (ER) and progesterone receptors $(\mathrm{PgR})$, proliferation index as assessed by $\mathrm{Ki}-67$ staining, and human epidermal receptor (HER)-2 status were evaluated on formalin-fixed, paraffin-embedded tumor tissue. Immunostainings for ER, PgR, and HER-2 were performed using the monoclonal antibodies 6F11 and 1A6 (Novocastra, Menarini, Florence, Italy) and the polyclonal antibody A0485 (Dako Denmark A/S, Glostrup, Denmark). Immunoreactions were revealed by a streptavidin-biotin enhanced immunoperoxidase technique (Super Sensitive MultiLink, Menarini) in an automated autostainer (Menarini). Diaminobenzidine was used as the chromogenic substrate. The tumors were considered to be positive for ER and $\mathrm{PgR}$ if $\geq 5 \%$ of the cells showed positive staining. The cutoff point for Ki-67 status was regarded as $>14 \%$ positively stained cells. HER-2 status was given in the pathology reports as $0,1+, 2+$, or $3+$ scores. Tumors with a score of 0 or $1+$ were regarded as HER-2-negative, and those with a score of $3+$ were regarded as HER-2-positive. Tumors with a $2+$ staining were tested for gene amplification by silver in situ hybridization (Hoffman-La Roche Ltd., Basel, Switzerland) or fluorescence in situ hybridization (Dako Denmark A/S). The molecular breast cancer subtypes were approximated taking into account ER, PgR, HER-2 status, and, when available, Ki67 proliferation index of the primary tumor. Patients were categorized as follows: luminal A (ER and/or PgR positive and HER-2 negative), luminal B-like (ER and/or PgR positive, HER-2 positive, Ki67 $\leq 14 \%$, or HER-2 negative with high Ki67 > 14), HER2-subtype (ER and PgR negative and HER-2 positive), and triple negative (ER, PgR, and HER-2 negative).

\section{Statistical analysis}

This prospective observational study planned an accrual of a total of 42 patients in order to estimate an ORR of $\sim 15 \%$ with a standard error of $5 \%$.

Data were summarized using descriptive statistics, absolute frequencies, and percentages when considering categorical variables and median and range when quantitative. The Kaplan-Meier method was used to estimate median time and survival rates for PFS and OS. IBM-SPSS Version 20 was used for all statistical analyses.

\section{Results}

A total of 42 patients were enrolled in this study. Table 1 shows their clinical characteristics. The median age was 48 years (range: $21-80$ years); most of the patients were in postmenopausal status; median Eastern Cooperative Oncology Group performance status was 0 (range: 0-2). Eight patients (19\%) had a triple-negative MBC.

All patients received a prior taxane-based therapy, mainly in the advanced disease $(66.7 \%)$. In particular, five patients had been administered a taxane-including regimen, either in the adjuvant or the metastatic setting. The median time elapsed from the previous taxane-containing adjuvant or metastatic treatment was 43 months (12-178 months) and 28 months (11-46 months), respectively. Previous anthracyclines were administered to $85.8 \%$ of the patients. All patients had previously received at least one first-line treatment for the metastatic disease (in $\sim 12 \%>$ four lines), and $80 \%$ of them had received also a previous hormonal therapy. The median number of metastatic sites was three (range: $1-4$ ), a visceral involvement being present in $\sim 78.5 \%$ of cases. 
Table I Demographic and clinical characteristics of patients

\begin{tabular}{|c|c|}
\hline Total number of patients & 42 \\
\hline Median age (years, range) & $48(21-80)$ \\
\hline \multicolumn{2}{|l|}{ ECOG performance status (median, \%) } \\
\hline 0 & 25 (59.5\%) \\
\hline 1 & 15 (35.7\%) \\
\hline 2 & $2(4.8 \%)$ \\
\hline \multicolumn{2}{|l|}{ Histologic subtypes (n, \%) } \\
\hline Luminal A & $10(23.8 \%)$ \\
\hline Luminal B-like HER2- & $19(45.2 \%)$ \\
\hline Luminal B-like HER2+ & $3(7.1 \%)$ \\
\hline HER2 like & $2(4.8 \%)$ \\
\hline Triple negative & $8(19 \%)$ \\
\hline Previous taxanes $(\mathrm{n}, \%)$ & $42(100 \%)$ \\
\hline Adjuvant setting & $19^{\mathrm{a}}(45.2 \%)$ \\
\hline Metastatic setting & $28(66.7 \%)$ \\
\hline \multicolumn{2}{|c|}{ Median time to previous taxanes (months, range) } \\
\hline Adjuvant & $43(12-178)$ \\
\hline Metastatic & $28(11-46)$ \\
\hline Previous anthracyclines (n, \%) & $36(85.8 \%)$ \\
\hline Adjuvant setting & $20(47.7 \%)$ \\
\hline Metastatic setting & $16(38 \%)$ \\
\hline Not done & $6(14.3 \%)$ \\
\hline \multicolumn{2}{|l|}{ Previous chemotherapy lines (n, \%) } \\
\hline I & $7(16.7 \%)$ \\
\hline 2 & $15(35.7 \%)$ \\
\hline 3 & $15(35.7 \%)$ \\
\hline$>4$ & $5(11.9 \%)$ \\
\hline Previous hormonal therapy $(\mathrm{n}, \%)$ & $32(80 \%)$ \\
\hline Median number of metastatic sites (range) & $3(I-4)$ \\
\hline \multicolumn{2}{|l|}{ Dominant metastatic site $(n, \%)$} \\
\hline Liver & $23(54.7 \%)$ \\
\hline Lung & $10(23.8 \%)$ \\
\hline Bone & $4(9.5 \%)$ \\
\hline Soft tissues & $5(11.9 \%)$ \\
\hline \multicolumn{2}{|l|}{ Nab-paclitaxel schedule (n, \%) } \\
\hline 3-weekly & $10(23.8 \%)$ \\
\hline Weekly & $32(76.2 \%)$ \\
\hline
\end{tabular}

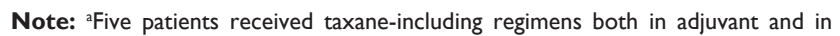
metastatic setting.

Abbreviations: HER2, human epidermal receptor 2; Nab, nanoparticle albumin bound; ECOG, Eastern Cooperative Oncology Group.

Ten patients (23.8\%) were given the 3-weekly schedule of $n a b$-paclitaxel and $32(76.2 \%)$ with weekly administration.

\section{Efficacy}

After a median number of six cycles (range: 1-11) (a total of 450 weekly administration given to patients), the ORR was $23.8 \%$, including one CR (2.4\%) and nine PR (21.4\%). A disease stabilization was obtained in eleven cases (26.2\%), for a disease control rate (DCR) of 50\% (Table 2). In the group of patients (total ten) who had 3-weekly schedule, only one patient achieved PR and four and five patients showed stability and progression of disease, respectively. The median duration of response was 7.2 months $(95 \%$ confidence interval: 6.7-8.7 months). Among the ten patients who received the 3-weekly schedule, one PR and four stability of disease were observed.
Table 2 Clinical response (global population: 42 patients)

\begin{tabular}{ll}
\hline Clinical response & Number (\%) \\
\hline Complete response & $\mathrm{I}(2.4)$ \\
Partial response & $9(2 \mathrm{I} .4)$ \\
ORR & $10(23.8)(95 \% \mathrm{Cl}[\mathrm{I} 2 . \mathrm{I}-39.5])$ \\
Stable disease & $\mathrm{II}(26.2)$ \\
Disease control rate & $2 \mathrm{I}(50)(95 \% \mathrm{Cl}[34.2-65.8])$ \\
Disease progression & $2 \mathrm{I} \mathrm{(50)}$ \\
\hline
\end{tabular}

Abbreviations: $\mathrm{ORR}$, overall response rate; $\mathrm{Cl}$, confidence interval.

The clinical response was also evaluated according to the previous chemotherapy lines (Table 3 ) and metastatic sites (Table 4). Among seven patients who received one previous line for metastatic disease, four (57\%) and two (28.5\%) partial responses and stable disease were observed, respectively; a total of 15 patients received two previous metastatic lines, one (7\%) and three (20\%) patients achieved complete and partial responses, respectively, and six (40\%) patients showed stability of disease. Among women given three lines of chemotherapy ( $\mathrm{n}=15)$, one PR (7\%), two SD $(13 \%)$, and 12 progression of disease $(80 \%)$ were registered, while in those treated with four lines $(\mathrm{n}=5)$, one PR $(20 \%)$ was documented. No difference was observed between the groups $(P=0.83)$. It is noteworthy that the best response is reached using $n a b$-paclitaxel in the early lines of chemotherapy (second or third line). Response by site was shown in Table 4; in particular, a DCR of $60 \%$ and $54 \%$, respectively, in lung and liver sites was observed.

After a median follow-up of 9 months (range: 2-38 months), the median PFS was 4.6 months $(95 \%$ confidence interval: $2.7-6.8$, range: 5-21+). Because a small cohort of patients was treated with 3-weekly schedule, no comparison between the two regimens in terms of efficacy was done.

Table 5 shows PFS according to previously administered chemotherapy. The median PFS in patients receiving up to two lines was 4.6 months, while it was 3.0 months in those receiving more than four lines of chemotherapy $(P=0.89)$. The median PFS in patients with less than two or with two more than two metastatic sites was 5.7 months and 3.7 months, respectively $(P=0.35)$. The median PFS in

Table 3 Clinical response, $\mathrm{n}(\%)$, according to previous chemotherapy lines

\begin{tabular}{lllll}
\hline Clinical response & $\begin{array}{l}\text { One line } \\
(\mathbf{n}=\mathbf{7})\end{array}$ & $\begin{array}{l}\text { Two lines } \\
(\mathbf{n}=\mathbf{1 5})\end{array}$ & $\begin{array}{l}\text { Three lines } \\
(\mathbf{n}=\mathbf{1 5})\end{array}$ & $\begin{array}{l}\text { Four lines } \\
(\mathbf{n}=\mathbf{5})\end{array}$ \\
\hline Complete response & 0 & $\mathrm{I}(7)$ & 0 & 0 \\
Partial response & $4(57)$ & $3(20)$ & $\mathrm{I}(7)$ & $\mathrm{I}(20)$ \\
Stable disease & $2(28.5)$ & $6(40)$ & $2(13)$ & $\mathrm{I}(20)$ \\
Disease progression & $\mathrm{I}(14)$ & $5(33)$ & $12(80)$ & $3(60)$ \\
\hline
\end{tabular}


Table 4 Clinical response according to different metastatic sites

\begin{tabular}{llllll}
\hline Site & N & \multicolumn{4}{l}{ Number (\%) } \\
\cline { 3 - 6 } & & CR & PR & SD & PD \\
\hline Lung & 15 & - & I (7) & $8(53)$ & $6(40)$ \\
Liver & 24 & - & $5(2 \mathrm{I})$ & $8(33)$ & II (46) \\
Bone & 12 & - & $9(75)$ & - & $3(25)$ \\
Soft tissues & 10 & I (I0) & $3(30)$ & $5(50)$ & I (I0) \\
Brain & 8 & - & - & $6(75)$ & $2(25)$ \\
\hline
\end{tabular}

Abbreviations: $\mathrm{CR}$, complete response; $\mathrm{PR}$, partial response; $\mathrm{SD}$, stable disease $\mathrm{PD}$, progression disease.

patients with only visceral metastases versus those without visceral metastases was 4.7 months and 4.6 months, respectively. All these differences were not statistically significant. Finally, the OS rate at 1 year was $53.8 \%$.

\section{Efficacy in accordance with biomolecular expression}

In Tables 6 and 7 are shown results regarding efficacy according to biomolecular expression of all patients. The response rate and DCR were slightly higher in luminal A tumors ( $30 \%$ and $60 \%$, respectively) than luminal B HER2-negative tumors (26\% and $53 \%$, respectively). A positive result was also observed in more aggressive breast cancer, such as triple-negative tumors (response rate $25 \%$ and DCR $50 \%$ ). By contrast, the positivity of HER 2 reduced the clinical efficacy induced by $n a b$-paclitaxel ( $0 \%$ and $33 \%$, respectively). The PFS was longer in triple-negative tumors (5.7 months) than in the other histotypes of MBC.

\section{Safety}

All the enrolled patients were assessable for safety analysis. The most frequent treatment-related toxicities were mild to moderate (grades 1-2). Neutropenia was the main grade 3/4 toxicity ( $70 \%)$, followed by leukopenia ( $25 \%)$, fatigue (13\%), and peripheral neuropathy (12\%) (Figure 1). Hematological toxicity was similar among patients who received both weekly and 3-weekly schedule; higher incidence of grade 2 peripheral neuropathy was documented in patients treated

Table 5 Progression-free survival according to previous chemotherapy lines, number of metastatic sites, and kind of metastasis

\begin{tabular}{llc}
\hline & $\begin{array}{l}\text { Progression-free } \\
\text { survival (months) }\end{array}$ & P-value \\
\hline$<2$ lines & $5.4(3.4-7.4)$ & 0.89 \\
$>2$ lines & $4.5(1.4-7.5)$ & \\
$<2$ metastatic sites & $5.7(2.8-8.5)$ & 0.35 \\
$>2$ metastatic sites & $3.7(1.2-6.2)$ & \\
Visceral metastasis & $4.7(1.5-7.9)$ & 0.43 \\
No visceral metastasis & $4.6(2.0-7.2)$ & \\
\hline
\end{tabular}

Table 6 Efficacy in accordance with biomolecular expression activity

\begin{tabular}{cllll}
\hline Histotypes & $\begin{array}{l}\text { Number } \\
\text { of patients }\end{array}$ & $\begin{array}{l}\text { Response } \\
\text { rate }(\mathbf{n}, \%)\end{array}$ & $\begin{array}{l}\text { Stable disease } \\
(\mathbf{n}, \%)\end{array}$ & $\begin{array}{l}\text { DCR } \\
(\mathbf{n}, \%)\end{array}$ \\
\hline $\begin{array}{l}\text { Luminal A } \\
\text { Luminal B }\end{array}$ & 10 & $3(30 \%)$ & $3(30 \%)$ & $6(60 \%)$ \\
HER2+ & 3 & 0 & $\mathrm{I}(33 \%)$ & $\mathrm{I}(33 \%)$ \\
HER2- & 19 & $5(26 \%)$ & $5(26 \%)$ & $10(53 \%)$ \\
HER2 like & 2 & 0 & 0 & 0 \\
Triple negative & 8 & $2(25 \%)$ & $2(25 \%)$ & $4(50 \%)$ \\
Total & 42 & $10(23.8 \%)$ & $11(26.2 \%)$ & $21(50 \%)$ \\
\hline
\end{tabular}

Abbreviations: DCR, disease control rate; HER2, human epidermal receptor 2.

with weekly $n a b$-paclitaxel ( $28 \%$ vs $12 \%$ ), and grade 3 was observed only in the weekly regimen.

\section{Discussion}

Taxanes have been widely demonstrated to be among the most active cytotoxic drugs for the treatment of breast cancer and, since their advent, provided a novel chemotherapy option in the treatment of patients with MBC. The novel solvent-free formulation of paclitaxel, nab-paclitaxel, has demonstrated a good safety and an efficacy profile compared with other taxanes, but no strong data to date are available about its role in taxane-pretreated MBC patients.

To our knowledge, this is the first study reporting the efficacy of $n a b$-paclitaxel in patients submitted to previous taxanes treatment, either in the adjuvant $(33 \%)$ or in the metastatic setting (67\%). Our results showed a global ORR in about a quarter and a DCR in a half of these highly compromised patients, regardless of the number of previous chemotherapy lines received. In the study by Blum et $\mathrm{a}^{10}$ taxane failure was defined as metastatic disease progression during taxane therapy or relapse within 12 months of adjuvant taxane therapy. These authors reported median PFS times of 3 months at $100 \mathrm{mg} / \mathrm{m}^{2}$ and 3.5 months at $125 \mathrm{mg} / \mathrm{m}^{2}$ and median survival times of 9.2 months and 9.1 months, respectively. By contrast, in our series, the median time elapsed from the previous taxane-containing adjuvant or metastatic

Table 7 Progression-free survival

\begin{tabular}{lll}
\hline Histotypes & $\begin{array}{l}\text { Number of } \\
\text { patients }\end{array}$ & $\begin{array}{l}\text { Median PFS } \\
\text { (months, 95\% CI) }\end{array}$ \\
\hline $\begin{array}{l}\text { Luminal A } \\
\text { Luminal B }\end{array}$ & 10 & $5.4(1.7-9.1)$ \\
HER2+ & 3 & $3.0(0.8-5.3)$ \\
HER2- & 19 & $4.7(4.2-5.2)$ \\
HER2 like & 2 & ne \\
Triple negative & 8 & $5.7(1.4-9.9)$ \\
\hline
\end{tabular}

Abbreviations: PFS, progression-free survival; $\mathrm{Cl}$, confidence interval; HER2, human epidermal receptor 2; ne, not evaluable. 


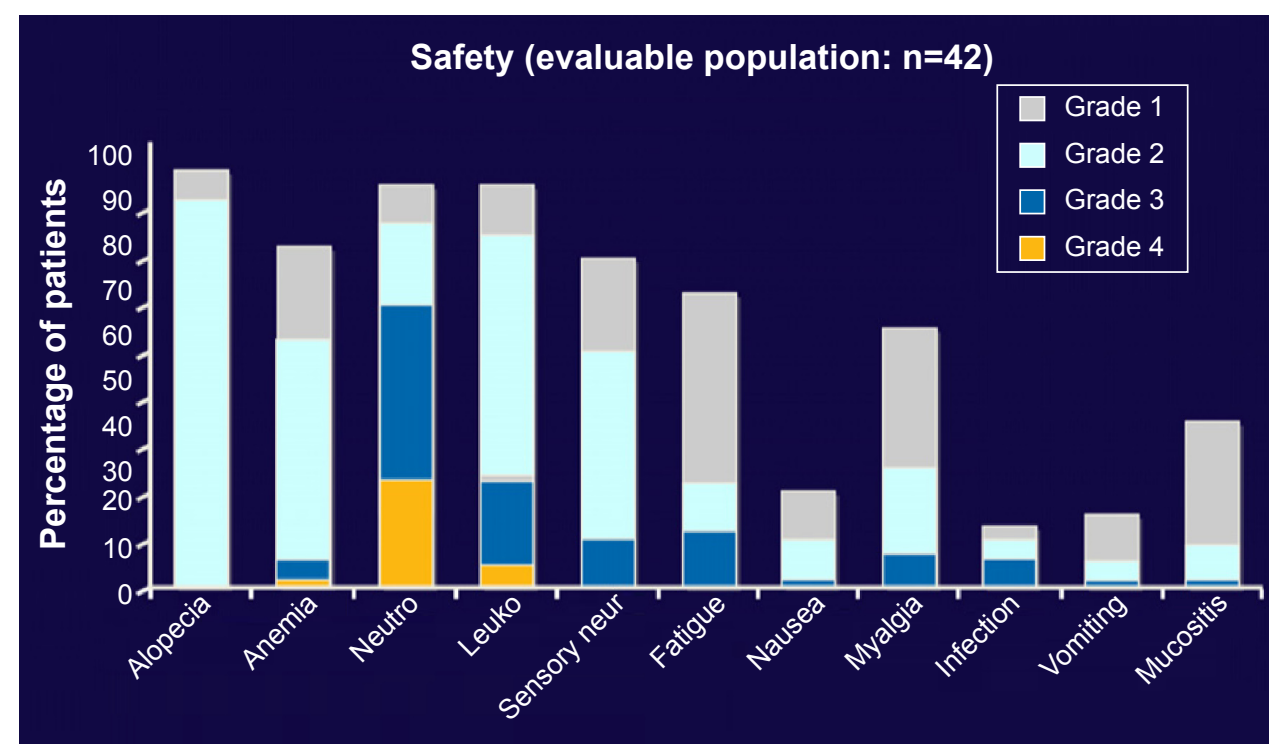

Figure I Main toxicity per patient observed in all study population. Both regimens (3-weekly [ten patients] and weekly [32 patients]) were cumulated in the figure. Abbreviations: Neutro, neutropenia; Leuko, leukopenia; Neur, neuropathy.

treatment was 43 months (range: $12-178$ ) and 28 months (range: 11-46), respectively. This fact could explain the quite longer PFS (4.6 months) and extremely longer OS (26 months) reported in our study.

Considering other experiences reported in the literature, our real-life results resemble those reported in the literature. In particular, in the Phase II and III studies evaluating nabpaclitaxel in monotherapy in the first-line treatment of patients with pretreated MBC, ORR ranged from $16 \%$ to $34 \%$, PFS ranged from 3.0 months to 6.6 months, and OS ranged from 9 months to 16.3 months. ${ }^{5,10,11}$ Although a better activity in patients treated with weekly schedule has been observed, we should not make an analysis comparing the two schedules for the different sample sizes between the two regimens. This is also the first study to demonstrate the activity of nab-paclitaxel in certain subtypes of patients, according to different metastatic sites. Furthermore, after a median follow-up of 9 months, the median PFS was 4.6 months; a similar value was observed in all the analyzed subgroups, regardless of the number of previous lines or metastatic sites.

It is interesting to note the activity of the drugs in all subtypes (Tables 6 and 7). It is noteworthy that the median PFS observed in the triple-negative population, which notoriously shows a poorer prognosis, resembled that registered in the luminal A group. As previously reported, $n a b$-paclitaxel is also active against more aggressive forms of MBC, such as triple-negative tumors. ${ }^{12,13}$ Probably when disease is in an advanced phase of evolution, as in our cohort of patients, and when patients are heavily pretreated, the value of biological features could be lost, and it is possible to note not a so deep difference in terms of results between the biological subtypes with the use of cytotoxic drugs.

The toxicity profile observed in our cohort is quite similar to that of other studies in pretreated patients, but with some differences. Neutropenia was the main grade $3 / 4$ toxicity observed in our study $(70 \%)$, which is slightly higher than that reported by Ibrahim et $\mathrm{al}^{11}$ (grade 4 neutropenia in $24 \%$ of patients, primarily during the first treatment cycle and managed with dose reduction, and grade 3 neutropenia in $27 \%$ of patients), but much higher than that reported in other two studies on pretreated patients (30\% and $34 \%$, respectively) ${ }^{5,10}$ The rate of grade 3/4 leukopenia (25\%) was lower than that reported by Blum et $\mathrm{al}^{10}(36 \%)$ but much higher than that of pivotal study on nab-paclitaxel. ${ }^{5}$ Grade $3 / 4$ peripheral neuropathy rate was $12 \%$ in our cohort, the same was observed by Ibrahim et $\mathrm{al}^{11}(11 \%)$ and Gradishar et $\mathrm{al}^{5}(10 \%)$, in both cases easily managed and improved rapidly to grade $1 / 2$. On the contrary, in the $125 \mathrm{mg} / \mathrm{m}^{2}$ cohort of the Blum study, 14 patients (19\%) developed grade 3 sensory neuropathy, three of whom had preexisting grade 1 peripheral neuropathy. These patients typically could be restarted on a reduced dose of albumin-bound paclitaxel after a 1- to 2-week delay. ${ }^{10}$ No new toxicity was detected in real-life management with $n a b$-paclitaxel of patients with pretreated MBC. We reported higher incidence of neuropathy in patients who were submitted to weekly administration of the drug $(125 \mathrm{mg} / \mathrm{mq} / \mathrm{w}$ ) (grade 2, 28\%; grade 3, 12\%). These data are likely to be referred to the higher dose-intensity administered drug in patients already treated with taxanes. 
A very recent prospective, multicenter study assessed the activity, safety, and quality of life of nab-paclitaxel $260 \mathrm{mg} / \mathrm{m}^{2}$ $\mathrm{q} 3 \mathrm{w}$ as second-line chemotherapy in 52 HER2-negative, taxane-pretreated $\mathrm{MBC}$ patients enrolled in three Italian centers. The ORR was $48 \%$, including $13.5 \%$ of $\mathrm{CR}$, and the overall CBR was $77 \%$. The median PFS was 8.9 months. The main grade $3 / 4$ toxicities observed in this study were leukopenia in $25 \%$ of patients, neutropenia in $21.2 \%$ of patients, and peripheral neuropathy in $5.8 \%$ of patients. The better activity and the lower rate of neutropenia and peripheral neuropathy reported by the authors were probably related to the use of this drug only in the second-line setting. ${ }^{15}$

\section{Conclusion}

In conclusion, this real-life study demonstrates that nabpaclitaxel, an innovative formulation of albumin-bound paclitaxel, has a significant antitumor activity and a manageable safety profile in patients pretreated with taxanes and experiencing a treatment failure after at least one line of chemotherapy; this cytotoxic drug was demonstrated to be active also in more aggressive breast cancers, such as triple-negative tumors. Furthermore, $n a b$-paclitaxel shows a number of advantages over existing taxanes, facilitating drug administration and improving patient acceptance, particularly due to the absence of premedication with corticosteroids or prolonged infusions or special intravenous infusion sets. The latter consideration is important in the general economy of care ${ }^{16}$ and the patient's quality of life.

\section{Disclosure}

The authors report no conflicts of interest in this work.

\section{References}

1. Cardoso F, Harbeck N, Fallowfield S, Kyriakides S, Senkus E; ESMO Guidelines Working Group. Locally recurrent or metastatic breast cancer: ESMO clinical practice guidelines for diagnosis, treatment and follow up. Ann Oncol. 2012;23(suppl 7):vii11-vii19.
2. Jones SE. Metastatic breast cancer: the treatment challenge. Clin Breast Cancer. 2008;8:224-233.

3. Gradishar WJ. Taxanes for the treatment of metastatic breast cancer. Breast Cancer. 2012;6:159-171.

4. The National Comprehensive Cancer Network, editor. National Comprehensive Network Clinical Practice Guidelines in Oncology, Breast Cancer, Version 1.2014; 2014. Available from: www.NCCN.org

5. Gradishar WJ, Tjulandin S, Davidson N, et al. Phase III trial of nanoparticle albumin-bound paclitaxel compared with polyethylated castor oil-based paclitaxel in women with breast cancer. J Clin Oncol. 2005;23:7794-7803.

6. Winer EP, Berry DA, Woolf S, et al. Failure of higher-dose paclitaxel to improve outcome in patients with metastatic breast cancer: Cancer and Leukemia Group B Trial 9342. J Clin Oncol. 2004;22:2061-2068.

7. Yardley DA. nab-Paclitaxel mechanisms of action and delivery. J Control Release. 2013;170:365-372.

8. Gradishar WJ, Krasnojon D, Cheporov S, et al. Significantly longer progression-free survival with nab-paclitaxel compared with docetaxel as first line therapy for metastatic breast cancer. J Clin Oncol. 2009;27:3611-3619.

9. Gradishar WJ, Krasnojon D, Cheporov S, et al. Phase II trial of nabpaclitaxel compared with docetaxel as first-line chemotherapy in patients with metastatic breast cancer: final analysis of overall survival. Clin Breast Cancer. 2012;12:313-321.

10. Blum JL, Savin MA, Edelman G, et al. Phase II study of weekly albuminbound paclitaxel for patients with metastatic breast cancer heavily pretreated with taxanes. Clin Breast Cancer. 2007;7:850-856.

11. Ibrahim NK, Samuels B, Page R, et al. Multicenter phase II trial of ABI-007, an albumin-bound paclitaxel, in women with metastatic breast cancer. J Clin Oncol. 2005;23:6019-6026.

12. Lobo C, Lopes G, Baez O, et al. Final results of a phase II study of nab-paclitaxel, bevacizumab, and gemcitabine as first-line therapy for patients with HER2-negative metastatic breast cancer. Breast Cancer Res Treat. 2010;123(2):427-435.

13. Hamilton E, Kimmick G, Hopkins J, et al. Nab-paclitaxel/bevacizumab/ carboplatin chemotherapy in first-line triple negative metastatic breast cancer. Clin Breast Cancer. 2013;13(6):416-420.

14. Therasse P, Arbuck SG, Eisenhauer EA, et al. New guidelines to evaluate the response to treatment on solid tumors. J Natl Cancer Inst. 2000;92(3):205-216.

15. Palumbo R, Sottotetti F, Trifirò G, et al. Nanoparticle albumin-bound paclitaxel (nab-paclitaxel) as second-line chemotherapy in HER2negative, taxane-pretreated metastatic breast cancer patients: prospective evaluation of activity, safety, and quality of life. Drug Des Devel Ther. 2015;9:1-11.

16. Lazzaro C, Bordonaro R, Cognetti F, et al. An Italian cost-effectiveness analysis of paclitaxel albumin (nab-paclitaxel) versus conventional paclitaxel for metastatic breast cancer patients: the COSTANza study. Clinicoecon Outcomes Res. 2013;5:125-135.

\section{Publish your work in this journal}

Drug Design, Development and Therapy is an international, peerreviewed open-access journal that spans the spectrum of drug design and development through to clinical applications. Clinical outcomes, patient safety, and programs for the development and effective, safe, and sustained use of medicines are a feature of the journal, which has also been accepted for indexing on PubMed Central. The manuscript management system is completely online and includes a very quick and fair peer-review system, which is all easy to use. Visit http://www.dovepress.com/testimonials.php to read real quotes from published authors. 